\title{
Current Treatment of Colorectal Liver Metastasis as a Chronic Disease
}

\author{
NIELS MICHAEL DÖRR ${ }^{1 *}$, MICHAEL BARTELS $^{1 *}$ and MEHMET HALUK MORGUL ${ }^{2}$ \\ ${ }^{1}$ Department of General, Visceral, Thoracic and Vascular Surgery, Helios Park-Klinikum Leipzig, Leipzig, Germany; \\ ${ }^{2}$ Department of General, Visceral and Transplantation Surgery, University of Münster, Münster, Germany
}

\begin{abstract}
Background/Aim: The treatment of colorectal liver metastases is challenging and requires multidisciplinary strategies. Unfortunately, only $25 \%$ of patients with colorectal liver metastases are eligible for liver resection. Due to the variety of therapeutic approaches, this percentage has increased; however, at the same time, the definition of resectability has become complex. The aim of this review was to provide an overview of current surgical therapies for colorectal liver metastases. Materials and Methods: Relevant studies published before June 2019 were identified using PubMed. A comprehensive review of the current literature regarding the impact of and innovations in the therapy of colorectal liver metastases was carried out. Results: The major advances in the resectability of colorectal liver metastases were effective chemotherapy regimens and preoperative liver volume modulation techniques. In addition, health professionals face rapid technical developments in interventional local therapies, minimally invasive surgery, robot-assisted surgery and even liver transplantation. Conclusion: Currently, liver metastases from colorectal cancer are considered a chronic disease. In cases of advanced colorectal liver metastases, the definition of resectability and the indications for surgical treatment should be exclusively determined by experienced hepatobiliary surgeons.
\end{abstract}

Colorectal cancer (CRC) is the third most frequent type of cancer and the fourth leading cause of cancer-related death worldwide. About $15-42 \%$ of patients with CRC have or develop liver metastases (1-4). Despite the high prevalence

This article is freely accessible online.

*These Authors contributed equally to this study.

Correspondence to: Dr. med. Niels-Michael Dörr, Prager Straße 129, 04317 Leipzig, Germany. Tel: +49 015752399632, e-mail: nielsdoerr@gmail.com

Key Words: Colorectal liver metastases, resectability, chronic disease, surgery. of liver metastasis, therapy for colorectal liver metastases (CRLMs) is still challenging and requires multidisciplinary strategies. Extensive achievements have been made in the systemic therapy for CRC as well as in local therapies for liver metastasis, such as ablation procedures (radiofrequency ablation, and microwave ablation) (5), regional hepatic intraarterial chemotherapy (6), chemoembolization (7), radioembolization (8), and radiation therapy, including stereotactic radiation therapy (9). Unfortunately, only $25 \%$ of patients with CRLM are eligible for liver resection (10, 11). Thus, the main question is how to define the resectability of metastasis (12-14). The aim of this review was to provide an overview of the current therapeutic options for CRLM by redefining surgical resectability.

\section{Materials and Methods}

Relevant and recent studies that focused on the treatment of CRLM and were published before June 2019 were identified using PubMed by searching for journal articles and colorectal liver metastases. A comprehensive review of the current literature regarding the impact of and innovations in therapy for colorectal liver metastases was carried out to provide guidelines for health professionals.

\section{Results}

Metachronous metastasis. The incidence of CRLM is approximately $12.8 \%$ in the five years following the diagnosis of primary CRC $(4,15)$. Primary surgery for liver metastasis, which ranges from a single subsegment resection to extensive bilateral resections, should still be considered as the primary therapy. Apart from the co-morbidities of the patients, the limitations of resection in most cases are the future of the remnant liver volume and poor liver function. Thus, when there is a disseminated pattern of metastases in the liver, it is challenging to perform extensive resection.

Since Adam et al. published their first series of two-stage hepatectomy (TSH) in 2000, TSH has been the most common curative approach for the surgical treatment of bilobar disease. TSH involves the surgical clearance of CRLM in one hemiliver during the first stage, followed by 
a second stage that includes the clearance of the contralateral hemiliver after hypertrophy to maintain a sufficient volume of the future liver remnant (16).

A systematic review showed that TSH is safe and effective in selected patients with primarily unresectable CRLM (17). TSH leads to significantly fewer complications and better overall survival (OS) than one-stage hepatectomy, which involves major hepatectomy and contralateral resection/ablation for bilobar disease (18). However, dropout rates after the first stage remain high due to poor liver regeneration and disease progression. Factors that are independently associated with poor OS following TSH are rectal primary tumors, more than five hepatic lesions, chemotherapy between the two stages and RAS mutations. RAS mutations are linked to worse long-term survival and are the only factor independently associated with OS and progression-free survival (PFS) for patients who underwent second-stage resection. Nevertheless, RAS mutations are not associated with dropout after the first stage (19).

A minimum of $25 \%$ of the liver volume has been considered as the minimum remnant volume for liver resection in healthy livers. However, functionality should also be considered (20). In cases with prior systemic chemotherapy, the remnant volume should be $30 \%$, and in cases with liver disease such as steatosis, at least $40 \%$ of the liver should be preserved after surgery (21). To induce growth of the future liver remnant, portal vein embolization (PVE) is a well-established intervention. PVE is considered the standard procedure prior to extended liver resection, which can otherwise jeopardize the remnant liver volume (22). The limitation of hypertrophy following PVE is mostly due to cholestatic disease or liver fibrosis (22). Seventy percent of patients could undergo surgery five weeks after PVE. Unfortunately, the progress of oncological disease is the predominant reason for dropout, followed by insufficient liver hypertrophy $(23,24)$. Additional hepatic vein embolization combined with PVE could be a safe alternative to induce faster hypertrophy in the future remnant liver; however, to date, the evidence for this procedure is weak (25).

Associated liver partition and portal vein ligation for staged hepatectomy (ALPPS) was introduced first as a rescue strategy in patients with biliary carcinoma. Later, ALPPS was evaluated in metastatic liver disease (26). ALPPS allows extended liver resection for bilateral diseases in shorter term compared to classical $\mathrm{TSH}$, with a 90-day mortality rate of $8.8 \%$ (27) and a morbidity rate of $56.3 \%$ (28). The first stage consists of tumor clearing in the left lateral liver segments, right portal vein ligation (PVL) and a so-called "in situ splitting", which is a complete parenchymal dissection while preserving the right hepatic artery, the right bile duct and the right hepatic vein. A major right hepatectomy is performed during the second stage (29). The advantage of this approach is the rapid hypertrophy of $74 \%$ (range $=21 \%-192 \%$ ) of the left lateral lobe in a median period of 9 days (range $=5-28$ days) (30). While there are high dropout rates after the first stage of TSH, in ALPPS, completion rates of $100 \%$ have been reported (31). The first prospective multicenter randomized controlled trial showed significantly higher resection rates for ALPPS than TSH, with similar mortality and morbidity (32). Thus, ALPPS can be considered an additional strategy for the treatment of advanced CRLM in patients with a very extensive tumor burden who are otherwise being considered for palliative treatment and as an intraoperative rescue strategy for cases with intraoperatively diagnosed advanced disease.

Synchronous metastasis. Patients with advanced synchronous CRLM with locally advanced rectal cancer are at risk for a poor outcome because liver disease may progress during the treatment of the primary CRC, especially if complications occur due to colorectal resection (33). The liver-first approach allows most patients with locally advanced rectal cancer and synchronous liver metastases to undergo curative resections of both metastatic and primary disease (34). As shown in small study groups, patients treated with the liver-first approach have a considerable OS and PFS, although disease-free survival (DFS) remains relatively low (35-37). The development of surgical techniques and the ability to perform liver and primary CRC resections with little blood loss, combined with advances in anesthesia and perioperative care, have made the synchronous approach an additional treatment option (38). However, the synchronous approach is still linked to postoperative morbidity and has a negative impact on PFS (39).

Minimally invasive liver resection. Since the introduction of laparoscopic liver surgery in 1992, this technique has become increasingly important for the operative management of CRLM (40). A systematic review of 4,967 patients indicated that laparoscopic liver resection had higher rates of clear surgical margin without significant differences in disease recurrence, OS and DFS compared to the open approach. Laparoscopic liver resection was associated with less intraoperative blood loss and fewer blood transfusions but also with longer operation times. Less overall morbidity and shorter postoperative hospital stays were observed for patients who underwent laparoscopic liver resection, while there was no significant difference in mortality (41). Even challenging surgical procedures such as laparoscopic posterior resections are associated with shorter hospital stays with similar oncological results (42). Recently, a study by Fretland et al. has shown that patients had a better life quality after the laparoscopic resection of CRLM than after the open approach in terms of both their physical and social recovery (43). 
The limitation of laparoscopic liver surgery is mostly related to the experience of the surgeon. While left and anterior segment resections can be performed by surgeons with low and intermediate experience levels, the resection of the posterior, especially the right superior sections, is highly advanced. Furthermore, obesity and thrombocytopenia can complicate the procedure (44). Robot-assisted liver resection might be a suitable option for surgically advanced cases (45).

Primary unresectable CRLM. While surgery is the only curative treatment approach for CRLM, only $25 \%$ of CRLMs are considered primarily resectable (46). Multifocal intrahepatic tumor spread in both liver lobes, extensive tumor burden or diffuse extrahepatic metastases result in either technical or functional unresectability or make the potential for curative treatment unlikely. Although bilateral CRLM was a contraindication for surgery in the past, over the past three decades, the therapy for advanced CRLM has changed and steadily improved; thus, the definition of resectability has changed. The most significant development in terms of resectability is the definition of the surgical margin in liver metastasis. Miller et al. have shown in a retrospective analysis that a minimum 1-mm surgical margin is sufficient for oncological clearance (47). On the other hand, significant developments have been made in chemotherapy regimens with the intention to downsize the metastases and achieve secondary resectability. Furthermore, surgical techniques for preoperative liver volume modulation, such as PVE, PVE in combination with left vein embolization $(48,49)$, TSH and ALPPS, have improved resectability, as described above (48).

Total vascular exclusion of the liver, vascular reconstruction (including hepatic veins), even ex situ hepatic resection and autologous transplantation, can be considered as surgical approaches for otherwise unresectable CRLM (30, 50). However, these techniques should be performed at experienced hepatobiliary units with a transplant background and should be considered only if no neoadjuvant options are available.

Perioperative chemotherapy. Neoadjuvant oxaliplatin- and irinotecan-based chemotherapy regimens in combination with 5-fluorouracil or leucovorin are currently first-line treatments for unresectable CRLM (51). Furthermore, classical regimens are combined with biologic agents such as bevacizumab and cetuximab and panitumumab for KRAS wild-type patients. The use of biologic agents combined with doublet chemotherapy regimens (FOLFOX or FOLFIRI) increases the resectability rate for initially unresectable CRLM. Furthermore, successful conversion results in outcomes similar to initially resectable CRLM (52-54). Due to downsizing by chemotherapy, between $13 \%$ and $54 \%$ of unresectable patients become resectable (51). On the other hand, nonresponse to neoadjuvant chemotherapy may be a contraindication for major hepatectomy in combination with ablation because of high local recurrence rates (55).

Findings by Lim et al. have shown an increase in OS with bevacizumab-based chemotherapy compared with conventional chemotherapy in a neoadjuvant setting for patients who underwent liver resection for synchronous CRLM. This benefit was shown in those who underwent primary tumor resection first. Bevacizumab had no impact on the liver-first approach (56). García-Alfonso et al. have retrospectively reviewed 74 patients treated with neoadjuvant or conversion chemotherapy plus bevacizumab. The authors emphasized that the OS was longer and that there was a trend for prolonged PFS and RFS in patients with a complete or major pathological response (57). However, in the patients who underwent staged surgical approaches, interval chemotherapy did not prevent disease progression or dropout rates before the second stage (58).

There is no clear evidence for additive chemotherapy following margin-negative liver resection; thus, there is no clear recommendation for the routine administration of chemotherapy $(59,60)$. However, a randomized controlled trial of 364 patients comparing perioperative chemotherapy with FOLFOX4 (folinic acid, fluorouracil, and oxaliplatin) before and after the surgical treatment of resectable CRLM to surgery alone showed no significant difference in OS between the two groups but a better PFS following preoperative chemotherapy. In contrast, the administration of perioperative chemotherapy has been associated with serious parenchymal liver damage and an increase in the postoperative morbidity-mortality rate (61). In cases of margin-positive resection, adjuvant chemotherapy should be considered since 54\% OS can be achieved (47).

Transplant oncology. Currently, there is an increasing emphasis on liver transplantation (LTx) as a treatment for CRLM (62). Because of poor OS before 1995, LTx was abandoned for otherwise unresectable CRLM $(63,64)$. The systemic spread of metastatic disease and LTX-associated postoperative immunosuppressive therapy may lead to increased recurrence in CRLM. Moreover, it is crucial to implement CRLM as an indication for LTx in light of the current donor shortage, since the prognosis of CRLM patients following LTx is not clear. However, advances in the treatment of CRLM and immunosuppression have led to a re-evaluation of this approach as a treatment option for unresectable CRLM (65).

Hagness et al. have published a prospective pilot study on 21 LTx cases with unresectable liver-only metastases (the SECA study). This study showed that the hepatic tumor load before LTx, time between primary surgery and transplantation, and progression despite chemotherapy were 
prognostic factors. The DFS after one year was 35\% (66). Two years later, Dueland et al. compared the results of the SECA study with first-line chemotherapy. The 5-year OS rate was $56 \%$ in patients undergoing LTx compared with $9 \%$ in patients starting first-line chemotherapy (67). A retrospectively collected cohort by Toso et al. with 12 selected patients attained similar results regarding OS (68).

In the course of the SECA study, 19 of the 21 patients experienced recurrence. Consequently, pulmonary recurrence appeared frequently and early but was relatively indolent. In contrast, patients who developed metastases to the transplanted liver had poor outcomes. In the SECA study, metastases to the transplanted liver appeared exclusively as a part of disseminated disease. Six of the seven patients who developed metastases to the transplanted liver died from metastatic disease. There where no first-site liver-only recurrences (69). According to Grut et al., patients treated by LTx for unresectable CRLM with pulmonary recurrence have a good prognosis following the resection of pulmonary metastases (70). Strict selection criteria for LTx in cases of unresectable CRLM have not yet been well defined, but tumor load, response to chemotherapy, pretransplant CEA level, and time interval from resection of the primary tumor to transplant are all related to outcome (62).

Finally, a fundamental limitation of this approach is the scarcity of liver grafts. A potential donor source is donation after cardiac death (DCD) or marginal grafts.

A possible strategy to address this scarcity could also be the so-called RAPID-Concept (Resection and Partial Liver Segment 2/3 Transplantation with Delayed Total Hepatectomy). The first stage of this strategy consists of liver resection of the left liver combined with transplantation of a left lateral section graft, usually from a living donor, and modulation of the graft portal inflow. This technique induces the fast regeneration of the transplanted graft during the course of two-three weeks. During the second stage, delayed total hepatectomy of the liver remnant is performed $(71,72)$. Currently, several worldwide studies are recruiting patients for the evaluation of LTx in the treatment of CRLM. More recently, a German group has launched a study based on the RAPID-Concept, which includes patients with unresectable CRLM, with stable disease or tumor regression after at least 8 weeks of systemic chemotherapy and without extrahepatic tumor growth (73).

\section{Conclusion}

The major advances in the resectability of CRLM are effective chemotherapy regimens with the intention to downsize the tumor and preoperative liver volume modulation techniques that affect the hypertrophy of the future remnant liver. Due to these developments, patients with CRLM commonly undergo various operations and interventions combined with chemotherapy during the course of their therapy. Thus, CRLM treatment has been transformed from being predominantly palliative to the management of a chronic disease. In addition to chemotherapy regimens and volume modulation, especially new surgical techniques, laparoscopy and even liver transplantation, are of crucial importance. Because of the technical developments in minimally invasive surgery, laparoscopic and robot-assisted surgery are pushing the boundaries of the resectability of liver metastasis in fatty livers following chemotherapy (74). Downsizing the metastases using preoperative chemotherapy and parenchyma-sparing surgery with the margins of $1-\mathrm{mm}$ allow a wide spectrum of therapeutic options for patients with CRLM. Thus, surgical and oncological improvements might dramatically increase the OS of those patients. Due to the variety of approaches, the assessment of resectability with modern surgical indications for the resection of CRLM has large disparities (13). Therefore, especially in cases of advanced CRLM, the definition of resectability and the indications for surgical treatment must be determined by experienced hepatobiliary surgeons.

\section{Conflicts of Interest}

The Authors declare that there are no conflicts of interest regarding this study.

\section{Authors' Contributions}

All Authors conceived of the presented idea. N.M.D. and M.H.M. conducted the review of the literature. M.B. and M.H.M verified the method. M.B. encouraged N.M.D. to investigate transplantation for colorectal metastasis and supervised the findings of this work. All Authors discussed the results and contributed to the final manuscript.

\section{References}

1 Gandomani HS, Yousefi SM, Aghajani M, MohammadianHafshejani A, Tarazoj AA, Pouyesh V and Salehiniya H: Colorectal cancer in the world: incidence, mortality and risk factors. Biomed Res Ther 4(10): 1656-1675, 2017. DOI: 10.15419/bmrat.v4i10.372

2 Mayo SC, Pulitano C, Marques H, Lamelas J, Wolfgang CL, de Saussure W, Choti MA, Gindrat I, Aldrighetti L, Barrosso E, Mentha G and Pawlik TM: Surgical management of patients with synchronous colorectal liver metastasis: a multicenter international analysis. J Am Coll Surg 216(4): 707-716, 2013. PMID: 23433970. DOI: 10.1016/j.jamcollsurg.2012.12.029

3 Pinson H, Cosyns S and Ceelen WP: The impact of surgical resection of the primary tumor on the development of synchronous colorectal liver metastasis: a systematic review. Acta Chir Belg 118(4): 203-211, 2018. PMID: 29783886. DOI: 10.1080/00015458.2018.1446602

4 Manfredi S, Lepage C, Hatem C, Coatmeur O, Faivre J and Bouvier AM: Epidemiology and management of liver metastases from colorectal cancer. Ann Surg 244(2): 254-259, 2006. PMID: 16858188. DOI: $10.1097 / 01$ sla.0000217629.94941.cf 
5 Meijerink MR, Puijk RS, van Tilborg AAJM, Henningsen KH Fernandez LG, Neyt M, Heymans J, Frankema JS, de Jong KP, Richel DJ, Prevoo W and Vlayen J: Radiofrequency and microwave ablation compared to systemic chemotherapy and to partial hepatectomy in the treatment of colorectal liver metastases: a systematic review and meta-analysis. Cardiovasc Intervent Radiol 41(8): 1189-1204, 2018. PMID: 29666906 DOI: $10.1007 / \mathrm{s} 00270-018-1959-3$

6 Allard MA and Malka D: Place of hepatic intra-arterial chemotherapy in the treatment of colorectal liver metastases. J Visc Surg 151: S21-24, 2014. PMID: 24636278. DOI: 10.1016/j.jviscsurg.2013.12.003

7 Fiorentini G, Aliberti C, Mulazzani L, Coschiera P, Catalano V, Rossi D, Giordani P and Ricci S: Chemoembolization in colorectal liver metastases: the rebirth. Anticancer Res 34(2): 575-584, 2014. PMID: 24510986.

8 Boas FE, Bodei L and Sofocleous CT: Radioembolization of colorectal liver metastases: indications, technique, and outcomes. J Nucl Med 58: 104S-111S, 2017. PMID: 28864605. DOI: 10.2967/jnumed.116.187229

9 Joo JH, Park JH, Kim JC, Yu CS, Lim SB, Park IJ, Kim TW, Hong YS, Kim KP, Yoon SM, Park J and Kim JH: Local control outcomes using stereotactic body radiation therapy for liver metastases from colorectal cancer. Int J Radiat Oncol Biol Phys 99(4): 876-883, 2017. PMID: 29063852. DOI: 10.1016/j.jirobp. 2017.07.030

10 Khatri VP, Petrelli NJ and Belghiti J: Extending the frontiers of surgical therapy for hepatic colorectal metastases: is there a limit. J Clin Oncol 23(33): 8490-8499, 2005. PMID: 16230676. DOI: $10.1200 / \mathrm{JCO} .2004 .00 .6155$

11 Folprecht G, Grothey A, Alberts S, Raab HR and Köhne CH: Neoadjuvant treatment of unresectable colorectal liver metastases: correlation between tumour response and resection rates. Ann Oncol 16(8): 1311-1319, 2005. PMID: 1587008. DOI: 10.1093/annonc/mdi2464

12 Mohammad WM, Martel G, Mimeault R, Fairfull-Smith RJ, Auer RC and Balaa FK: Evaluating agreement regarding the resectability of colorectal liver metastases: a national casebased survey of hepatic surgeons. HPB (Oxford) 14(5): 291297, 2012. PMID: 22487066. DOI: 10.1111/j.14772574.2012.00440.x

13 Aubin JM, Bressan AK, Grondin SC, Dixon E, MacLean AR, Gregg S, Tang P, Kaplan GG, Martel G and Ball CG: Assessing resectability of colorectal liver metastases: How do different subspecialties interpret the same data. Can J Surg 61(4): 251256, 2018. PMID: 30067183.

14 Norén A, Sandström P, Gunnarsdottir K, Ardnor B, Isaksson B, Lindell $\mathrm{G}$ and Rizell $\mathrm{M}$ : Identification of inequalities in the selection of liver surgery for colorectal liver metastases in Sweden. Scand J Surg 107(4): 294-301, 2018. PMID: 29692213. DOI: $10.1177 / 1457496918766706$

15 Lemke J, Cammerer G, Ganser J, Scheele J, Xu P, Sander S, Henne-Bruns D and Kornmann M: Survival and prognostic factors of colorectal liver metastases after surgical and nonsurgical treatment. Clin Colorectal Cancer 15(4): e183-e192, 2016. PMID: 27269232. DOI: 10.1016/j.clcc.2016.04.007

16 Adam R, Laurent A, Azoulay D, Castaing D and Bismuth H: Two-stage hepatectomy: A planned strategy to treat irresectable liver tumors. Ann Surg 232(6): 777-785, 2000. PMID: 11088072. DOI: 10.1097/00000658-200012000-00006
17 Lam VW, Laurence JM, Johnston E, Hollands MJ, Pleass HC and Richardson AJ: A systematic review of two-stage hepatectomy in patients with initially unresectable colorectal liver metastases. HPB (Oxford) 15(7): 483-491, 2013. PMID: 23750490. DOI: $10.1111 / j .1477-2574.2012 .00607 . x$

18 Bowers KA, O'Reilly D, Bond-Smith GE and Hutchins RR: Feasibility study of two-stage hepatectomy for bilobar liver metastases. Am J Surg 203(6): 691-697, 2012. PMID: 22154136. DOI: $10.1016 /$ j.amjsurg .2011 .07 .014

19 Passot G, Chun YS, Kopetz SE, Zorzi D, Brudvik KW, Kim BJ, Conrad C, Aloia TA and Vauthey JN: Predictors of safety and efficacy of 2-stage hepatectomy for bilateral colorectal liver metastases. J Am Coll Surg 223(1): 99-108, 2016. PMID: 26968325. DOI: 10.1016/j.jamcollsurg.2015.12.057

20 Shoup M, Gonen M, D'Angelica M, Jarnagin WR, DeMatteo RP, Schwartz LH, Tuorto S, Blumgart LH and Fong Y: Volumetric analysis predicts hepatic dysfunction in patients undergoing major liver resection. J Gastrointest Surg 7(3): 325-330, 2003. PMID: 12654556. DOI: 10.1016/s1091-255x(02)00370-0

21 Zorzi D, Laurent A, Pawlik TM, Lauwers GY, Vauthey JN and Abdalla EK: Chemotherapy-associated hepatotoxicity and surgery for colorectal liver metastases. Br J Surg 94(3): 274-286, 2007. PMID: 17315288. DOI: 10.1002/bjs.5719

22 Shimada S, Kamiyama T, Yokoo H, Orimo T, Wakayama K, Nagatsu A, Kakisaka T, Kamachi H, Abo D, Sakuhara Y and Taketomi A: Hepatic hypertrophy and hemodynamics of portal venous flow after percutaneous transhepatic portal embolization. BMC Surg 19(1): 23, 2019. PMID: 30777042. DOI: 10.1186/ s12893-019-0486-8

23 Ironside $\mathrm{N}$, Bell $\mathrm{R}$, Bartlett $\mathrm{A}$, McCall $\mathrm{J}$, Powell $\mathrm{J}$ and Pandanaboyana S: Systematic review of perioperative and survival outcomes of liver resections with and without preoperative portal vein embolization for colorectal metastases. HPB (Oxford) 19(7): 559-566, 2017. PMID: 28438427. DOI: 10.1016/j.hpb.2017.03.003

24 van Lienden KP, van den Esschert JW, de Graaf W, Bipat S, Lameris JS, van Gulik TM and van Delden OM: Portal vein embolization before liver resection: a systematic review. Cardiovasc Intervent Radiol 36(1): 25-34, 2013. PMID: 22806245. DOI: $10.1007 / \mathrm{s} 00270-012-0440-y$

25 Esposito F, Lim C, Lahat E, Shwaartz C, Eshkenazy R, Salloum $\mathrm{C}$ and Azoulay D: Combined hepatic and portal vein embolization as preparation for major hepatectomy: a systematic review. HPB (Oxford) 21(9): 1099-1106, 2019. PMID: 30926329. DOI: 10.1016/j.hpb.2019.02.023

26 Schlitt HJ, Hackl C and Lang SA: 'In-situ split' liver resection/ALPPS - Historical development and current practice. Visc Med 33(6): 408-412, 2017. PMID: 29344513. DOI: $10.1159 / 000479850$

27 Schadde E, Raptis DA, Schnitzbauer AA, Ardiles V, Tschuor C, Lesurtel M, Abdalla EK, Hernandez-Alejandro R, Jovine E, Machado M, Malago M, Robles-Campos R, Petrowsky H, Santibanes ED and Clavien PA: Prediction of mortality after ALPPS Stage-1: An analysis of 320 patients from the International ALPPS Registry. Ann Surg 262(5): 780-785, 2015. PMID: 26583666. DOI: 10.1097/SLA.0000000000001450

28 Sun Z, Tang W, Sakamoto Y, Hasegawa K and Kokudo N: A systematic review and meta-analysis of feasibility, safety and efficacy of associating liver partition and portal vein ligation for staged hepatectomy (ALPPS) versus two-stage hepatectomy 
(TSH). Biosci Trends 9(5): 284-288, 2015. PMID: 26559020. DOI: $10.5582 /$ bst.2015.01139

29 Schadde E, Schnitzbauer AA, Tschuor C, Raptis DA, Bechstein WO and Clavien PA: Systematic review and meta-analysis of feasibility, safety, and efficacy of a novel procedure: associating liver partition and portal vein ligation for staged hepatectomy. Ann Surg Oncol 22(9): 3109-3120, 2015. PMID: 2544879. DOI: 10.1245/s10434-014-4213-5

30 Oldhafer KJ, Stavrou GA and van Gulik TM: ALPPS--Where do we stand, where do we go? Eight recommendations from the first international expert meeting. Ann Surg 263(5): 839-841, 2016. PMID: 26756771. DOI: 10.1097/SLA.0000000000001633

31 Schnitzbauer AA, Lang SA, Goessmann H, Nadalin S, Baumgart J, Farkas SA, Fichtner-Feigl S, Lorf T, Goralcyk A, Hörbelt R, Kroemer A, Loss M, Rümmele P, Scherer MN, Padberg W, Königsrainer A, Lang H, Obed A and Schlitt HJ: Right portal vein ligation combined with in situ splitting induces rapid left lateral liver lobe hypertrophy enabling 2-staged extended right hepatic resection in small-for-size settings. Ann Surg 255(3): 405-414, 2012. PMID: 22330038. DOI: 10.1097/SLA.0b013e31824856f5

32 Sandström P, Røsok BI, Sparrelid E, Larsen PN, Larsson AL, Lindell G, Schultz NA, Bjørnbeth BA, Isaksson B, Rizell M and Björnsson B: ALPPS improves resectability compared with conventional two-stage hepatectomy in patients with advanced colorectal liver metastasis: Results From a Scandinavian Multicenter Randomized Controlled Trial (LIGRO Trial). Ann Surg 267(5): 833-840, 2018. PMID: 28902669. DOI: 10.1097/SLA.0000000000002511

33 Mentha G, Majno PE, Andres A, Rubbia-Brandt L, Morel P and Roth AD: Neoadjuvant chemotherapy and resection of advanced synchronous liver metastases before treatment of the colorectal primary. Br J Surg 93(7): 872-878, 2006. PMID: 16671066. DOI: $10.1002 /$ bjs. 5346

34 Verhoef C, van der Pool AE, Nuyttens JJ, Planting AS, Eggermont AM and de Wilt JH: The "liver-first approach" for patients with locally advanced rectal cancer and synchronous liver metastases. Dis Colon Rectum 52(1): 23-30, 2009. PMID: 19273952. DOI: 10.1007/DCR.0b013e318197939a

35 van der Wal GE, Gouw AS, Kamps JA, Moorlag HE, Bulthuis ML, Molema G and de Jong KP: Angiogenesis in synchronous and metachronous colorectal liver metastases: the liver as a permissive soil. Ann Surg 255(1): 86-94, 2012. PMID: 22156924. DOI: 10.1097/SLA.0b013e318238346a

36 de Jong MC, van Dam RM, Maas M, Bemelmans MH, Olde Damink SW, Beets GL and Dejong CH: The liver-first approach for synchronous colorectal liver metastasis: a 5-year singlecentre experience. HPB (Oxford) 13(10): 745-752, 2011. PMID: 21929676. DOI: 10.1111/j.1477-2574.2011.00372.x

37 Sturesson C, Valdimarsson VT, Blomstrand E, Eriksson S, Nilsson JH, Syk I and Lindell G: Liver-first strategy for synchronous colorectal liver metastases - an intention-to-treat analysis. HPB (Oxford) 19(1): 52-58, 2017. PMID: 27838252. DOI: $10.1016 /$ j.hpb.2016.10.005

38 Fong Y, Fortner J, Sun RL, Brennan MF and Blumgart LH: Clinical score for predicting recurrence after hepatic resection for metastatic colorectal cancer: analysis of 1001 consecutive cases. Ann Surg 230(3): 309-318, 1999. PMID: 10493478. DOI: 10.1097/00000658-199909000-00004

39 de Haas RJ, Adam R, Wicherts DA, Azoulay D, Bismuth H, Vibert E, Salloum C, Perdigao F, Benkabbou A and Castaing D:
Comparison of simultaneous or delayed liver surgery for limited synchronous colorectal metastases. Br J Surg 97(8): 1279-1289, 2010. PMID: 20578183. DOI: 10.1002/bjs.7106

40 Gagner M, Rheault $M$ and Dubuc J: Laparoscopic partial hepatectomy for liver tumor. Surg Endosc 6: 97-98, 1992.

41 Xie SM, Xiong JJ, Liu XT, Chen HY, Iglesia-García D, Altaf K, Bharucha S, Huang W, Nunes QM, Szatmary P and Liu XB: laparoscopic versus open liver resection for colorectal liver metastases: a comprehensive systematic review and metaanalysis. Sci Rep 7(1): 1012, 2017. PMID: 28432295. DOI: 10.1038/s41598-017-00978-z.

42 Okuno M, Goumard C, Mizuno T, Omichi K, Tzeng CD, Chun YS, Aloia TA, Fleming JB, Lee JE, Vauthey JN and Conrad C: Operative and short-term oncologic outcomes of laparoscopic versus open liver resection for colorectal liver metastases located in the posterosuperior liver: a propensity score matching analysis. Surg Endosc 32(4): 1776-1786, 2018. PMID: 28917012. DOI: 10.1007/s00464-017-5861-x

43 Fretland ÅA, Dagenborg VJ, Waaler Bjørnelv GM, Aghayan DL, Kazaryan AM, Barkhatov L, Kristiansen R, Fagerland MW, Edwin B and Andersen MH: Quality of life from a randomized trial of laparoscopic or open liver resection for colorectal liver metastases. Br J Surg 106(10): 1372-1380, 2019. PMID: 31322735 DOI: $10.1002 /$ bjs. 11227

44 Fung AKY and Lee KF: Robotic resection for posterosuperior liver lesions: is it really superior to laparoscopic resection. Hepatobiliary Surg Nutr 8(3): 264-266, 2019. PMID: 31245409. DOI: $10.21037 / \mathrm{hbsn} .2018 .12 .12$

45 Hasegawa Y, Wakabayashi G, Nitta H, Takahara T, Katagiri H, Umemura A, Makabe $\mathrm{K}$ and Sasaki A: A novel model for prediction of pure laparoscopic liver resection surgical difficulty. Surg Endosc 31(12): 5356-5363, 2017. PMID: 28593408. DOI: $10.1007 / \mathrm{s} 00464-017-5616-8$

46 Scheele J, Stang R, Altendorf-Hofmann A and Paul M: Resection of colorectal liver metastases. World J Surg 19(1): 59-71, 1995. PMID: 7740812. DOI: 10.1007/bf00316981

47 Miller CL, Taylor MS, Qadan M, Deshpande V, Worthington S, Smalley R, Collura C, Ryan DP, Allen JN, Blaszkowsky LS, Clark JW, Murphy JE, Parikh AR, Berger D, Tanabe KK, Lillemoe KD and Ferrone CR: Prognostic significance of surgical margin size after neoadjuvant FOLFOX and/or FOLFIRI for colorectal liver metastases. J Gastrointest Surg 21(11): 1831-1840, 2017. PMID: 28884391. DOI: $10.1007 / \mathrm{s} 11605-017-3557-0$

48 Lang H, Baumgart J and Mittler J: Associating liver partition and portal vein ligation for staged hepatectomy in the treatment of colorectal liver metastases: Current Scenario. Dig Surg 35(4): 294-302, 2018. PMID: 29621745. DOI: 10.1159/000488097

49 Bismuth H, Adam R, Lévi F, Farabos C, Waechter F, Castaing D, Majno $\mathrm{P}$ and Engerran L: Resection of nonresectable liver metastases from colorectal cancer after neoadjuvant chemotherapy. Ann Surg 224(4): 509-520; discussion 520-522, 1996. PMID: 8857855. DOI: 10.1097/00000658-199610000-00009

50 Heaney JP, Stanton WK, Halbert DS, Seidel J and Vice T: An improved technic for vascular isolation of the liver: experimental study and case reports. Ann Surg 163(2): 237-241, 1966. PMID: 4286023. DOI: $10.1097 / 00000658-196602000-00013$

51 Wicherts DA, de Haas RJ and Adam R: Bringing unresectable liver disease to resection with curative intent. Eur J Surg Oncol 33: S42-51, 2007. PMID: 17981429. DOI: 10.1016/ j.ejso.2007.09.017 
52 Nozawa H, Ishihara S, Kawai K, Hata K, Kiyomatsu T, Tanaka T, Nishikawa T, Otani K, Yasuda K, Sasaki K, Kaneko M and Murono K: Conversion to resection in patients receiving systemic chemotherapy for unresectable and/or metastatic colorectal cancer-predictive factors and prognosis. Clin Colorectal Cancer 17(1): e91-e97, 2018. PMID: 29113730. DOI: 10.1016/j.clcc.2017.10.002

53 Poston G, Adam R, Xu J, Byrne B, Esser R, Malik H, Wasan H and $\mathrm{Xu} \mathrm{J}$ : The role of cetuximab in converting initially unresectable colorectal cancer liver metastases for resection. Eur J Surg Oncol 43(11): 2001-2011, 2017. PMID: 28927777. DOI: 10.1016/j.ejso.2017.07.021

54 Nordlinger B, Adam R, Arnold D, Zalcberg JR, Gruenberger T: The role of biological agents in the resection of colorectal liver metastases. Clin Oncol (R Coll Radiol) 24(6): 432-442, 2012. PMID: 22794325. DOI: 10.1016/j.clon.2012.01.002

55 Mao R, Zhao JJ, Zhao H, Zhang YF, Bi XY, Li ZY, Zhou JG, $\mathrm{Wu} \mathrm{XL}, \mathrm{Xiao} \mathrm{C}$ and Cai JQ: Non-response to preoperative chemotherapy is a contraindication to hepatectomy plus radiofrequency ablation in patients with colorectal liver metastases. Oncotarget 8(43): 75151-75161, 2017. PMID: 29088853. DOI: 10.18632 /oncotarget.20647

56 Lim C, Doussot A, Osseis M, Esposito F, Salloum C, Calderaro J, Tournigand C and Azoulay D: Bevacizumab improves survival in patients with synchronous colorectal liver metastases provided the primary tumor is resected first. Clin Transl Oncol 20(10): 12741279, 2018. PMID: 29594943. DOI: 10.1007/s12094-018-1858-8

57 García-Alfonso P, Cavanagh Podesta M, Muñoz Martín A, Blanco Codeisido M, Calvo A, Peligros I, Corcuera A, Belén Rúperez Blanco A, Custodio-Cabello S, López Trabada D, Martín M and DE Ramón E: Chemotherapy plus bevacizumab as neoadjuvant or conversion treatment in patients with colorectal liver metastases. Anticancer Res 38(5): 3069-3077, 2018. PMID: 29715142. DOI: 10.21873/anticanres.12564

58 Muratore A, Zimmitti G, Ribero D, Mellano A, Viganò L and Capussotti L: Chemotherapy between the first and second stages of a two-stage hepatectomy for colorectal liver metastases: should we routinely recommend it. Ann Surg Oncol 19(4): 13101315, 2012. PMID: 21947627. DOI: 10.1245/s10434-011-20695

59 Mitry E, Fields AL, Bleiberg H, Labianca R, Portier G, Tu D, Nitti D, Torri V, Elias D, O'Callaghan C, Langer B, Martignoni G, Bouché O, Lazorthes F, Van Cutsem E, Bedenne L, Moore MJ and Rougier P: Adjuvant chemotherapy after potentially curative resection of metastases from colorectal cancer: a pooled analysis of two randomized trials. J Clin Oncol 26(30): 49064911, 2008. PMID: 18794541. DOI: 10.1200/JCO.2008.17.3781

60 Nishioka Y, Moriyama J, Matoba S, Kuroyanagi H, Hashimoto $\mathrm{M}$ and Shindoh J: Prognostic impact of adjuvant chemotherapy after hepatic resection for synchronous and early metachronous colorectal liver metastases. Dig Surg 35(3): 187-195, 2018. PMID: 28848205. DOI: 10.1159/000478791

61 Polastro L, El Hachem G and Hendlisz A: Pseudoadjuvant chemotherapy in resectable metastatic colorectal cancer. Curr Opin Oncol 30(4): 269-275, 2018. PMID: 29762149. DOI: $10.1097 / \mathrm{CCO} .0000000000000455$

62 Line PD, Hagness M and Dueland S: The potential role of liver transplantation as a treatment option in colorectal liver metastases. Can J Gastroenterol Hepatol 2018: 8547940, 2018. PMID: 29623266. DOI: 10.1155/2018/8547940
63 Foss A, Adam R and Dueland S: Liver transplantation for colorectal liver metastases: revisiting the concept. Transpl Int 23(7): 679-685, 2010. PMID: 20477993. DOI: 10.1111/j.14322277.2010.01097.x

64 Mühlbacher F, Huk I, Steininger R, Gnant M, Götzinger P, Wamser $\mathrm{P}$, Banhegyi $\mathrm{C}$ and Piza F: Is orthotopic liver transplantation a feasible treatment for secondary cancer of the liver. Transpl Proc 23(1 Pt 2): 1567-1568, 1991. PMID: 1989293.

65 Moris D, Tsilimigras DI, Chakedis J, Beal EW, Felekouras E, Vernadakis S, Schizas D, Fung JJ and Pawlik TM: Liver transplantation for unresectable colorectal liver metastases: A systematic review. J Surg Oncol 116(3): 288-297, 2017. PMID: 28513862. DOI: $10.1002 /$ jso. 24671

66 Hagness M, Foss A, Line PD, Scholz T, Jørgensen PF, Fosby B, Boberg KM, Mathisen O, Gladhaug IP, Egge TS, Solberg S, Hausken J and Dueland S: Liver transplantation for nonresectable liver metastases from colorectal cancer. Ann Surg 257(5): 800-806, 2013. PMID: 23360920. DOI: 10.1097/SLA.0b013e3182823957

67 Dueland S, Guren TK, Hagness M, Glimelius B, Line PD, Pfeiffer P, Foss A and Tveit KM: Chemotherapy or liver transplantation for nonresectable liver metastases from colorectal cancer. Ann Surg 261(5): 956-960, 2015. PMID: 24950280. DOI: $10.1097 /$ SLA.0000000000000786

68 Toso C, Pinto Marques H, Andres A, Castro Sousa F, Adam R, Kalil A, Clavien PA, Furtado E, Barroso E and Bismuth H: Liver transplantation for colorectal liver metastasis: Survival without recurrence can be achieved. Liver Transpl 23(8): 1073-1076, 2017. PMID: 28544246. DOI: 10.1002/lt.24791

69 Hagness M, Foss A, Egge TS and Dueland S: Patterns of recurrence after liver transplantation for nonresectable liver metastases from colorectal cancer. Ann Surg Oncol 21(4): 13231329, 2014. PMID: 24370906. DOI: 10.1245/s10434-013-3449-9

70 Grut H, Solberg S, Seierstad T, Revheim ME, Egge TS, Larsen SG, Line PD and Dueland S: Growth rates of pulmonary metastases after liver transplantation for unresectable colorectal liver metastases. Br J Surg 105(3): 295-301, 2018. PMID: 29168565. DOI: $10.1002 /$ bjs.10651

71 Line PD, Hagness M, Berstad AE, Foss A and Dueland S: A novel concept for partial liver transplantation in nonresectable colorectal liver metastases: The RAPID Concept. Ann Surg 262(1): e5-9, 2015. PMID: 25692361. DOI: 10.1097/SLA. 0000000000001165

72 Hernandez-Alejandro R and Wall WJ: The RAPID conceptnovel idea or a bridge too far. Ann Surg 262(1): e10-11, 2015. PMID: 26020116. DOI: 10.1097/SLA.0000000000001269

73 Rauchfuß F, Nadalin S, Königsrainer A and Settmacher U: Living donor liver transplantation with two-stage hepatectomy for patients with isolated, irresectable colorectal liver-the LIVER-T(W)O-HEAL study. World J Surg Oncol 17(1): 11, 2019. PMID: 30621712. DOI: 10.1186/s12957-018-1549-5

74 Cipriani F, Fantini C, Ratti F, Lauro R, Tranchart H, Halls M, Scuderi V, Barkhatov L, Edwin B, Troisi RI, Dagher I, Reggiani P, Belli G, Aldrighetti L and Abu Hilal M: Laparoscopic liver resections for hepatocellular carcinoma. Can we extend the surgical indication in cirrhotic patients. Surg Endosc 32(2): 617626, 2018. PMID: 28717870. DOI: 10.1007/s00464-017-5711-x

Received September 5, 2019

Revised October 5, 2019

Accepted November 5, 2019 